Finisterra, Xxv, 50, Lisboa, 1990, p. 261-298.

\title{
LAS TRANSFORMACIONES EN LOS USOS DE LAS PROPIEDADES MILITARES EN ESPAÑA
}

\author{
JOSÉ IGNACIO MURO MORALES
}

\section{INTRODUCCIÓN}

Este artículo $\left(^{1}\right)$ tiene como objetivo mostrar el proceso de desafectación de grandes extensiones de propiedades en manos del Estado desde el año 1984, en particular las militares. En un intento de establecer paralelismos y diferencias nos remontaremos a períodos anteriores para mostrar las coincidencias o las diferencias en casos concretos. Las razones que subyacen en la transformación de los usos militares de la propiedad urbana son diversas. En la actualidad, la más general intenta razonar su intencionalidad debido a la financiación de una prolongada y costosa modernización de las

(1) Este trabajo no hubiera sido posible sin la amable y afectuosa invitación a participar en el Plano Estratégico para a Preservação e Valorização do Património Arquitectónico e Urbanistico de Lisboa, em Relação com o Desenvolvimento Ścio-Económico (VALIS), realizado por el Centro de Estudos e Desenvolvimento Regional è Urbano, promovido por la Comisión de las Comunidades Europeas (Dir. Ger. Política Regional), y coordinado por el Profesor Catedrático JoRGe GaSPAR y el Dr. José MANuEL FERnANDEs. A los coordinadores del proyecto, así como a la Dra. Lucinda FonsecA y al resto de colegas agradezco sinceramente todas las facilidades para ver impreso este texto que deriva de un trabajo inédito con el título Alienação das Propriedades Urbanas do Ministério de Defesa de Espanha, Lisboa, CEDRU, mayo 1991. En este capítulo de agradecimientos no puedo olvidar a las autoridades del Ministerio de Defensa español y en particular a los responsables de la GINDEF por haberme proporcionado el material de base para las reflexiones que siguen. 
fuerzas armadas, favoreciendo la desurbanización militar o si se quiere la desmilitarización de las ciudades. Pueden buscarse numerosos ejemplos históricos de este proceso, derivados de la estatalización de la propiedad, las desamortizaciones, la reprivatización u otros. En estos momentos se estan produciendo otros procesos similares en grandes empresas del Estado, como la RENFE o grandes propietarios y otros organismos de la administración pública. En una primera parte vamos a remarcar el proceso de expansión urbana en la España del siglo xIx, como un ejemplo de desafectación militar de algunas áreas urbanas derivadas del derribo de las murallas, y donde aparecerán litigios sobre límites de la propiedad, polémicas institucionales e intereses especulativos.

En la segunda parte de este trabajo expondremos las características del proceso de desafectación de unos bienes propiedad del estado y su reversión en forma de convenios, proyectos y futuras revalorizaciones de amplias zonas de las ciudades españolas. Finalmente, el último apartado aborda las características formales del conjunto de intervenciones poniendo el énfasis en los grandes proyectos de renovación y transformación como Madrid, Barcelona o Gerona, mostrando algunos ejemplos distintos de negociación entre las diversas administraciones públicas e instituciones privadas, y su concrección en forma de convenios, de interés para todas las partes en litigio.

Gestión de las Propiedades MILITARES en la EsPaña DECIMONónica, entre el Conflicto de INTERESES Y El CAMBIO dE ORIENTACION MILITAR EN EL ASENTAMIENTO URBANO

Desde la Revolución Francesa hasta el final de la Guerra de la Independencia, el interés por la conservación de la mayoría de las fortificaciones y estructuras defensivas españolas aumentó significativamente debido a su destrucción, por un lado, y a su obsolescencia y estado lamentable, por otro. La reforma integral de las fortificaciones (plan de defensa estable) no se llevó nunca a cabo $\left({ }^{2}\right)$. Esa es una de las razones

(2) MURo, 1991. 
por la preferencia en el aprovechamiento de las estructuras edificatorias desamortizadas, ya que la crisis financiera $\mathrm{y}$ de la hacienda $\left({ }^{3}\right)$ tampoco ayudaron al presupuesto de obras $\mathrm{y}$ nuevas construcciones con destino al sostenimiento y reestructuracion de las fortificaciones a los nuevos tiempos. Hay que destacar, por su excepcionalidad, las refortificaciones de antiguos recintos amurallados, relacionados con las guerras civiles españolas del siglo XIX. En todo caso, corporaciones militares como los ingenieros actuaron de forma decisiva en los ámbitos urbanos dentro de una política urbanística gobernada por los capitanes generales $\left({ }^{4}\right)$.

La estrutura defensiva y las zonas polémicas que aquella originaba en el territorio debían ser integradas en los aspectos más amplios que acabarían dando sentido a las mismas: la movilidad de los ejércitos y su nueva estructura, la organización, los caminos y carreteras, puertos, ferrocarriles y desarrollo urbano. En cuanto al asentamiento defensivo en los núcleos de población derivó antes y después de 1854 hacía una política redistributiva de los cuarteles $y$ edificios militares, que aún tardaría en implantarse y generalizarse; primero más allá de los antiguos centros históricos y luego fuera del núcleo urbano propiamente dicho. En el caso de Cataluña, el abandono de antiguos recintos amurallados $\left(^{5}\right)$ planteaba la cuestión de donde colocar el grueso del ejército activo. Desde los primeros intentos desamortizadores de la hacienda liberal, antiguos conventos $\mathrm{y}$ edificios religiosos pasaron a manos de la administración militar, organizándose la instalación de cuarteles inmersos en los cascos urbanos, disponiendo de este modo de antiguos, pero amplios recintos. Esto confería una territorialización ligada a la presencia militar en áreas de alta conflictividad social, hecho por otro lado presente en la agitada vida social del Ochocientos. Sin embargo, ni la distribución de plazas fuertes cumplía ya con su antigua función de articulación de supuestas líneas defensivas estáticas sobre el territorio, ni el reparto de edificios militares $y$ cuarteles obedecía a limitar a defender las zonas polémicas de costas

(') Fontana, 1980 .

(i) Garcia y GUARdia, 1986.

(5) ESTAPE, 1967. 
y fronteras. En general existía una gran coincidencia entre el mal estado de los edificios y cuarteles, y los grandes núcleos de población, como eran los casos de Barcelona, Gerona y Tarragona $\left({ }^{\mathrm{B}}\right)$.

\section{Las zonas polémicas del espacio urbano}

La polémica sobre las murallas de las ciudades constituyó la punta del iceberg de un problema más complejo y antiguo. Las áreas circundantes a las fortificaciones eran consideradas de carácter estratégico, por lo que en éstas era imposible la expansión urbana. Este hecho implicó políticas de intervención sobre las áreas de dominación militar, no superadas hasta pasada la segunda mitad del siglo xIx. Las murallas no atendían suficientemente los propósitos de defensa de la ciudad industrial, salvo en los conflictos sociales, al tiempo que creaban problemas añadidos. Los conflictos sociales de mediados del siglo xIX influirán en el inicio de la polémica sobre el derribo de las murallas que todavía circundaban las ciudades, y nos permiten conocer la evolución de antiguas formas de control sobre el espacio urbano. También son posibles otros acercamientos, ya que las ideas militares sobre la ciudad pueden rastrearse a través de los cambios producidos en el arte de la fortificación, en la distribución del ramo militar en las urbes allí donde existieron guarniciones, en las relaciones entre el ejército y la administración del Estado, así como en la evolución de la realidad física del paisaje urbano.

Hasta el cuestionamiento generalizado de los entornos fortificados, la atención por el plano de la ciudad por parte de las fuerzas armadas estaba basado en la continuidad de normativas y prácticas de control que limitaban la expansión urbana y la construcción más allá de los muros fortificados. Este hecho produjo litigios por el usufructo de un espacio infrautilizado.

En las primeras décadas del siglo xIx, las ciudades españolas comienzan a sentir los cambios producidos en la demografía y en los sistemas de producción. Las urbes amuralladas $\mathrm{y}$ con fuertes densidades demográficas internas nos

(') Memoria ... 1873. 
aparecen con un espacio exterior casi vacío. Grupos de presión en demanda de suelo urbanizable comenzarán a dar forma a la idea de ensanche ilimitado, así como las primeras peticiones de anulación de consideraciones estratégicas para el entorno urbano. De forma individual o colectiva, dichos grupos originarán los llamados «expedientes de las zonas polémicas» donde pueden detectarse los enfrentamientos a antiguas formas de control, para favorecer el derribo de los límites amuralados, el crecimiento de la ciudad y la libre edificación en estas áreas. El conflicto de competencias territoriales entorno al área amurallada de las ciudades se agudizó en un periodo bastante largo (1830-1875) y no acabará, en ciertos casos, hasta el cambio de siglo.

Los nuevos tiempos cambian las barreras físicas por otros condicionamientos estratégicos $\mathrm{y}$ en tres años se autorizan los ensanches de Madrid y Barcelona (1857-1859). En el caso de Barcelona, el Ministerio de la Guerra se reservaba, a cambio de un ensanche ilimitado, el modo $y$ la forma de venta de los terrenos de las zonas polémicas abandonadas. También se reservaba, en los proyectos de ensanche, la potestad de elección de las áreas donde situar los futuros recintos de las fuerzas armadas, idea relacionada con un proyecto global de transladar cuarteles y regimientos del centro de las ciudades al extrarradio, y aprovechar así las nuevas estructuras urbanas.

Los ensanches de las poblaciones empezaron a regularse por criterios esencialmente civiles, entrando en conflicto con las autoridades militares por las previstas permutas de terrenos, su valoración, y por las disputas sobre la propiedad de los terrenos de las antiguas fortificaciones. Decía un ingeniero militar en 1888 que «resulta más ventajoso que aprovechar las murallas antiguas derribarlas, tal es cuando una ciudad ha aumentado mucho su importancia, y los terrenos ocupados por las fortificaciones pueden venderse a precios elevados» $\left({ }^{7}\right)$.

Todo este panorama general no es un hecho aislado para el caso español. El caso de Paris resulta interesante, por su importancia $y$ por su conocimiento generalizado. El nuevo cinturón de fortificaciones construido de 1841 a 1845 fuera de los límites administrativos de la ciudad produjo discusiones

(') DE LA LIAVE Y GaRCIA, 1887-88, p. 88. 
entre los militares europeos. En todo caso, la valoración sobre el auténtico significado defensivo de las fortificaciones de Paris, de $36 \mathrm{kms}$. de longitud, iba más allá de las necesarias inversiones para llevarlas a cabo. Tras los acontecimientos revolucionarlos del 48 cambiarán los criterios sobre la intervención en la ciudad antigua. Así, en el plan de G.-E. HAUsSMANN destacaban, entre otras, las motivaciones estratégicas y policiales. La reforma urbana del antiguo Paris estaba basada en arterias contínuas para el avance de las tropas, en una mayor anchura de las vías para hacer difícil el levantamiento de barricadas y el lanzamiento de proyectiles improvisados desde los tejados, así como en la localización estratégica de acuartelamientos y centrales de policia $\left({ }^{8}\right)$.

Los mecanismos de recambio de la propiedad: la expropiación, la enajenación, la venta y alquiler de los bienes patrimoniales

Antes de pasar a analizar la situación y las implicaciones de la desafectación patrimonial por parte del Estado en nuestros días nos gustaría ofrecer un panorama general sobre esa misma problemática en la España del siglo xIX. El objetivo de esa transgresión histórica es doble. Por un lado, el más general, mostrar que el estudio de la geografía histórica de un país tiene diversas formas de aproximación dada la complejidad del Estado, esa forma político-social que la sociedad contemporánea se ha dado para su propia organización. Esta, como veremos, no es monolítica ni uniforme en sus criterios de funcionamiento. Dentro de su estructura existieron y por supuesto existen divergencias de intereses y conflictos que conviene esclarecer para entender la evolución de las actuaciones realizadas sobre el territorio.

Por otro lado, queremos mostrar que el proceso de enajenación de grandes propiedades tal como ho'y se está efectuando no es enteramente novedoso. Es posible analizar y estudiar parecidos fenómenos en el pasado, aunque con otras formas, con otros protagonistas, y tal vez con otros resultados para la ciudad de finales de este siglo.

( $\left.{ }^{8}\right)$ SICA, 1981, vol. 2 y DUBY, G., 1982, vol. 4. 
La venta de los bienes ligados al Estado tuvo en el siglo XIX numerosas figuras jurídicas y métodos de actuación y apropiación diversos, relacionados con los profundos abismos del mismo Estado. En general suele tomarse como punto de inflexión importante las reglas que regularon las desamortizaciones fallidas o los conceptos de bienes públicos a partir de entonces. En los inicios de la andadura liberal, una Ley de 1836 (Ley 14 de Julio 1836) sobre la enajenación forzosa de la propiedad en beneficio público definía por obra de utilidad pública aquella que tiene por objeto directo proporcionar al Estado en general, o a una o más provincias, o a uno o más pueblos, cualquier uso o disfrute de beneficio común. La aplicación de este amplio concepto del bien estatal a las propiedades militares era todavía más restrictiva debido a la actividad de esta poderosa institución en la España contemporánea. Así, el Reglamento para la aplicación a los casos de guerra de la Ley sobre enajenación forzosa de la propiedad particular en beneficio publico (Real Decreto 13 julio 1863) consideraba como de carácter militar los siguientes territorios:

- Terrenos, edificios y demás propiedades necesarias para estaciones telegráficas de las líneas que se dispongan con el objeto de que contribuyan a la defensa del Estado.

- Terrenos, casas y cualquiera otra propiedad que en el interior y al exterior de las plazas de guerra sean indispensables para el establecimiento de cuarteles, almacenes $y$ otras instalaciones.

- Terrenos y propiedades que sean precisos en las plazas de guerra y demás puntos que parezcan más acomodados para campos permanentes de instrucción.

- Los necesarios para construir nuevos cuarteles y otros edificios de las dependencias de Guerra en las capitales en que están establecidas las Capitanias Generales, y en aquellas poblaciones elegidas para el acuartelamiento de tropas.

La venta y administración de estos bienes utilizados por el Ministerio de la Guerra correspondía a la Hacienda Pública, mientras que los Ingenieros militares fijaban las condiciones de traspaso y la Administración Militar arreglaba los contratos. 
Durante buena parte del siglo XIX el producto de estas transacciones se aplicaba a un fondo denominado Material de Ingenieros, dedicado en general a las obras militares y controlado por los mismos ingenieros. Los expedientes de compra y venta, en cualquier caso, se sometían a la aprobación política antes de ser decididas. En este contexto, las fincas del Ministerio de la Guerra eran propiedad del Estado, consideradas afectadas al servicio de esa administración, debiendo entregarse a la Hacienda cuando ya no fueran necesarias (Orden 22 octubre 1870).

En un intento de establecer criterios más justos en el reparto de la propiedad, la Ley de Desamortización (1 de mayo 1855) declaró en venta todos los prédios rústicos y urbanos, censos y foros pertenecientes al Estado, al clero, a las ordenes militares $y$ cualquier otro bien de propiedad de las manos muertas. Se exceptuaron los edificios y fincas destinadas a servicio público, y los que por razones graves no juzgara oportuna su venta. Entre estos se encontraban los militares, respecto de los cuales una Real Orden de 25 de diciembre de 1855 determinó que no se procediera a su enajenación mientras no se declarase por el ministerio su inutilidad para el servicio y la correspondiente entrega a hacienda, como encargada por dicha ley de efectuar las ventas. El objetivo de estas ventas resultó ser cubrir el déficit del presupuesto del año 1855 y 1856, la amortización de la deuda del Estado español y por último la realización de obras públicas. Las presiones del ejército hicieron que en 1856 se revocase esta disposición y otra ley de 5 de marzo de 1856 exceptuaba de aquellos destinos las cantidades que produjera la enajenación de los terrenos y edificios militares pertenecientes al ministerio y que fueron declarados inútiles.

El destino final de la venta de esos inmuebles y propiedades iba destinado a mejorar la situación de edificios y fortificaciones, o a la construcción de nueva planta. Volvían por este modo a ingresar los fondos del Material de Ingenieros.

Estas disposiciones rigieron hasta la suspensión de las leyes desamortizadoras en 1857. Entonces, la reacción conservadora resolvió que las propiedades declaradas inútiles para el Ministerio de la Guerra, no debían entregarse a la Hacienda, sino que otro organismo militar, la Administración Militar, 
debía gestionar su futuro. Un año después, en 1858, se publicaban las reglas que establecían los trámites y formalidades necesarias. A costa de hacer un poco pesada esta evolución histórica vamos a señalarlas por su interés y por que surgen en un momento en que se está negociando el futuro de grandes extensiones de suelo y propiedades en las ciudades donde se inician los ensanches fuera del corse que supusieron las murallas $\mathrm{y}$ porque tienen muchas connotaciones actualistas.

«Los Comandantes de Ingenieros de las Plazas, presentarán la medición y tasación de las fincas o terrenos que hayan de enajenarse, redactando el pliego de condiciones para la subasta, y pasando estos documentos al Dir. Subinspector, el que los remitirá a su vez, de oficio y con su informe al Intendente, para que adicione los que correspondan a la Administración Militar, tales como el plazo en que se ha de verificar el pago, y fianza que deba exigirse a los postores. Cuando el valor de la finca o terreno que se enajenara no llegase a 20000 reales, se publicará la subasta desde luego, anunciándola la Intendencia del distrito con 30 dias por lo menos de anticipación y por medio de edictos (...), y verificada aquella, se adjudicará el remate a la postura más ventajosa, formalizándose la escritura de venta y dándose conocimiento al Gobierno. Cuando el valor de la finca o terreno excediese de 20000 reales se pasará el pliego de condiciones por conducto del Ingeniero General a la aprobación de S. M. y no se considerará consumada la subasta, hasta que obtuviese igual aprobación» $\left({ }^{9}\right)$.

Este acuerdo tampoco fue satisfactorio para la política de la época y al año siguiente (1859) la venta de bienes militares enajenados pasó a la hacienda civil, aunque entonces con bastantes prerrogativas para la administración militar. Esta situación duraría hasta el régimen moderado de Narváez, al final de los años sesenta. Entonces, todos los expedientes de venta de propiedades del ministerio pasaron, cualquiera que

(') Circular 13 febrero 1858, cit. en Memoria... 1873, p. 756. 
fuere su valor, a la Dirección General de Administración Militar.

Los resultados de esta polémica institucional en el mismo corazón de la administración del Estado tuvo escasos resultados en el orden práctico, aunque marcaron el rumbo a seguir para futuras actuaciones y modificaciones de la propiedad estatal. Después de los hechos revolucionarios de setiembre de 1868 una ley (30 de junio de 1869) autorizaba al gobierno para vender en pública subasta distintas propiedades: en Valencia, el cuartel de San Francisco y en Madrid el ex-convento del Carmen, las oficinas de la Administración Militar y el denominado cuartel del Soldado. El importe de la venta debía revertir en la construcción de cuarteles y en la reparación de edificios militares en mal estado.

Otra modalidad de obtener recursos para los declarados fines fue el alquiler de las numerosas propiedades no necesarias en distintos momentos. Las dificultades de entendimiento entre Hacienda y el Ministerio de la Guerra desde el advenimiento del Liberalismo provocaron también que en esta materia se articularán formas restrictivas y particulares. Bajo esta forma de utilización de la propiedad también se extendían convenios por los cuales los arrendatarios estaban obligados a entregar las cantidades acordadas a las Tesorerias Públicas (después llamadas Cajas de las Administraciones Económicas).

Los políticos del período revolucionario (1868-1874) todavía introdujeron algunas modificaciones de interés en este panorama. En síntesis, la administración económica civil dejaba el usufructo de las propiedades a la administración militar, pero una vez desafectada, o sea, declarada fuera del interés militar, pasaba a manos de la primera para enajenar, conservar o cualquier otra operación conveniente para los intereses generales del Estado $\left({ }^{10}\right)$. De forma pormenorizada mostramos algunas de las reglas señaladas en 1870:

«1. Todas las fincas del Estado dependen de Hacienda, por ser este ramo el representante de los derechos o propiedades de aquel; pero las que se hallen afectas

${ }^{(10)}$ Ley 22 octubre de 1870 para la entrega, conservación y reparación de los edificios militares, cit. en Memoria... 1873. 
al servicio de Guerra, están a cargo exclusivo de este ministerio durante todo el tiempo que las necesite.

«2. Las propiedades del Estado que son necesarias para el servicio del Ministerio de la Guerra, son entregadas a éste por el de Hacienda, y aquel debe considerarse como mero usufructuario mientras las necesite, deviendo devolverlas a la expresada Hacienda pública tan pronto como no pueda darles destino útil, a fín de que ésta las enajene, conserve o dedique a lo que crea más conveniente a los intereses generales del Estado.

«3. El cuerpo administrativo del ejército es el representante legal de todos los derechos y propiedades del Estado afectos al servicio de Guerra, y a éste corresponde por consiguiente, tener inventarios de todas las fincas, intervenir en todas las entregas, representar en juício y fuera de él al Ramo de Guerra en todo lo que concierne $\mathrm{y}$ puede interesar a la integridad $\mathrm{y}$ demás prerrogativas inherentes al derecho de propiedad.

«11. Las fortificaciones y edificios de nueva planta levantados o adquiridos con fondos del presupuesto de Guerra, no se entenderá por esto que son propiedad de dicho ramo, sino del Estado, afectas al servicio de Guerra y por consiguiente se entregarán a la Hacienda, cuando ya no tengan aplicación para el servicio militar».

Al menos por el espíritu de la letra, los cambios propugnados por la sociedad civil en el régimen de la propiedad del mismo Estado fueron entonces notorios. Además se introdujeron algunas novedades significativas. Entre ellas, las más destacables hacían referencia a la posibilidad de revertir, conceder o ceder determinados edificios a otras administraciones, como las municipales, o a empresas o particulares. Estaban exceptuados de esta posibilidad los edificios declarados monumentos históricos o artisticos (11). 
Demoliciones, cesiones, permutas $y$ ventas

Tras la guerra de la Independecia española (1808-1814) y la guerra carlista (1836-1839) se hacía imprescindible reordenar y recuperar el maltrecho sistema defensivo constituido por plazas y puntos fuertes. Es entonces, una vez finalizado el reinado absoluto de Fernando VII, cuando empiezan a surgir reflexiones críticas sobre una articulación territorial de la defensa heredera de la obra del siglo xvin. Durante ese siglo se definiría en España una política defensiva basada en la urbanización y la fortificación de las plazas portuarias y zonas costeras, dejando descuidadas las fronteras terrestres y el interior. Fue a finales del Setecientos, cuando cambiaron las políticas de alianzas internacionales, y el peligro de invasión no fue $\tan$ remoto, que empezaron a elaborarse planes de defensa generales y proyectos de fortificación de áreas supestamente desprotegidas, aunque con escasas realizaciones concretas $\left({ }^{12}\right)$.

El número de plazas fuertes sufrió un constante descenso a lo largo del siglo XIX, de tal forma que en la década de los cuarenta alcanzaban la cifra de 145 , y treinta años más tarde (Sexénio Democrático) se habían reducido a 80 . De éstas plazas más de la mitad se encontraban necesitadas de mejoras, o en estado de ruina. $Y$ de esas últimas tan sólo 5 se encontraban en buenas condiciones: Cádiz, Santoña, Ferrol, Cartagena y Ceuta ${ }^{\left({ }^{13}\right)}$. El año 1854 se autorizaba el derribo de las murallas de la ciudad de Barcelona y se iniciaba el proceso de elaboración del plan de ensanche ilimitado, que aún tardaría unos años en concretizarse. Pocos años después comenzaba el abandono de estructuras poco funcionales. La Real Orden de 22 de enero de 1859 mandaba abandonar las plazas y fuertes siguientes: Ayamonte, Bayona, La Guardia, Almeria, castillo de Jaca, Albuquerque, Valencia de Alcántara y la Ciudadela de Valencia. La destrucción de las fortificaciones se debía dejar a la acción del tiempo, y los terrenos y edificios militares interiores venderse con arreglo a la Ley de Desamortización. En Alicante, donde también debían desaparecer

(12) CAPEL, H., 1982, pp. 293-95.

(13) FernáNdez BaSTARReChe, 1978, pp. 27-30 y MUro, 1990. 
las fortificaciones, se mandó conservar el castillo de Santa Barbara y los fuertes exteriores, y en San Sebastián el castillo de la Mota. En ambas ciudades debían desaparecer las murallas por derribo.

También en Albuquerque y Valencia de Alcántara debían conservarse los castillos, mientras que en la antigua Ciudadela de Valencia debía construirse un nuevo cuartel. En otras fortificaciones como Molina de Aragón, Berga, Denia, Peñas de San Pedro, Castrourdiales, Motril, Olivenza, Guetaria y Ciudadela (Menorca) no debía invertirse ninguna cantidad en su mejora, mandándose demoler donde fuera necesario. En cuanto a la acción contraria, la refortificación, apenas tuvo efectividad. Como ejemplo quedan las obras de la nueva fortaleza de Isabel II (La Mola) en Mahon (Menorca). En 1864 se suspendieron las obras por falta de fondos, reanudándose en 1867 , para suspenderse en 1868 .

Dos gobiernos revolucionarios, el de $1854 \mathrm{y}$ el de 1868 , autorizaron el desmantelamiento de las estructuras fortificadas de la ciudad de Barcelona ${ }^{\left({ }^{4}\right)}$. Sin embargo, las condiciones de este profundo cambio, tan positivo para el crecimiento urbano, dejaron una importante hipoteca a la misma ciudad. La polémica sobre el valor y la propiedad de los terrenos amurallados también iba a influir en el diseño urbano. Una vez derribadas las murallas de la plaza fuerte de Barcelona, en 1868 se autorizó al Ayuntamiento de esta ciudad a derribar el recinto de su Ciudadela, el fuerte Pío, la cortina de Atarazanas y los edificios de Junqueras y Jerusalen. En un principio, la administración militar conservó los edificios de la Ciudadela $y$ de Atarazanas.

El solar de la Ciudadela de Barcelona se cedió gratuitamente al Ayuntamiento de esta ciudad. Para medir la importancia de esta cesión diremos que este solar media $608807 \mathrm{~m}^{2}$ (fig. 1), posteriormente sede de la Exposición Universal de Barcelona de 1888. En las condiciones de cesión se establecián el ensanchar la vía pública y crear parques y jardines, así como que los gastos de demolición corrieran a cargo del

( ${ }^{14}$ Gobierno Mititar, 1868, Archivo de la Corona de Aragón, Fondo Comand. Ing., Caja 352. Decreto 26 octubre 1868, Archivo de la Corona de Aragón, Fondo Comand. Ing., Caja 325. 
municipio, haciendo a éste responsable de indemnizar a los propietarios que legalmente justificaran tener ese derecho. Asimismo, el Ayuntamiento se comprometía a construir por su cuenta el cuartel o cuarteles que fueran necesarios para alojar el número de soldados de la presente Ciudadela.

Entre las consideraciones del convenio de cesión también se incluían otros de carácter propiamente urbanístico. El techo de edificación no podía superar los $53000 \mathrm{~m}^{2}$. Si la corporación municipal sobrepasaba este límite debía abonar al Estado el uno y medio por ciento del precio a que vendiese la porción edificable. Además, si el terreno destinado a parque o via pública cambiase de objeto o aplicación urbanística, el Estado se reservaba todos los derechos anteriores.

La causa del conflicto de intereses entre la administración del Estado y la corporación municipal vino de la mano de los derechos que el Ministerio de la Guerra creía conculcados por parte de la institución urbana. Así, durante los años 70 se inició la polémica con los terrenos de la muralla de mar (fig. 1) sobre la cual no hubo ningún acuerdo, modificándose profundamente la topografía anterior y su funcionalidad, sin definir ninguna contrapartida para los anteriores usufructuadores y alargándose hasta finales de siglo ${ }^{\left({ }^{15}\right)}$. Este fue uno de los motivos de la firma de un convenio entre el Ayuntamiento de Barcelona y el ministerio de Defensa en el año 1877, al que seguirían otros hasta el remate total de la antigua área fortificada.

La actuación de la institución municipal en materia urbanística era plena una vez aprobado en 1859 el ensanche del ingeniero de caminos ILDEFONSO CERDA. Sin embargo, hasta finales de siglo no empezó a notarse verdaderas transformaciones en la nueva área, futuro ensanche ${ }^{\left({ }^{10}\right)}$. En este panorama $y$ con el antecedente de las murallas del frente marítimo de la ciudad, la administración militar comenzó una tarea jurídica, amparándose en la administración de la hacienda, para hacer valer sus derechos. La primera tarea fue realizar

$\left({ }^{15}\right)$ Comandancia, 1878, Archivo de la Corona de Aragón, Fondo Comand. Ing., Exp. 2646. Comandancia, 1878, Archivo de la Corona de Aragón, Fondo Comand. Ing., Caja 404. MiNisterio DE LA GUERRA, 1884-1887.

( $\left.{ }^{18}\right)$ AJUNTAMENT DE Barcelona, 1990. 


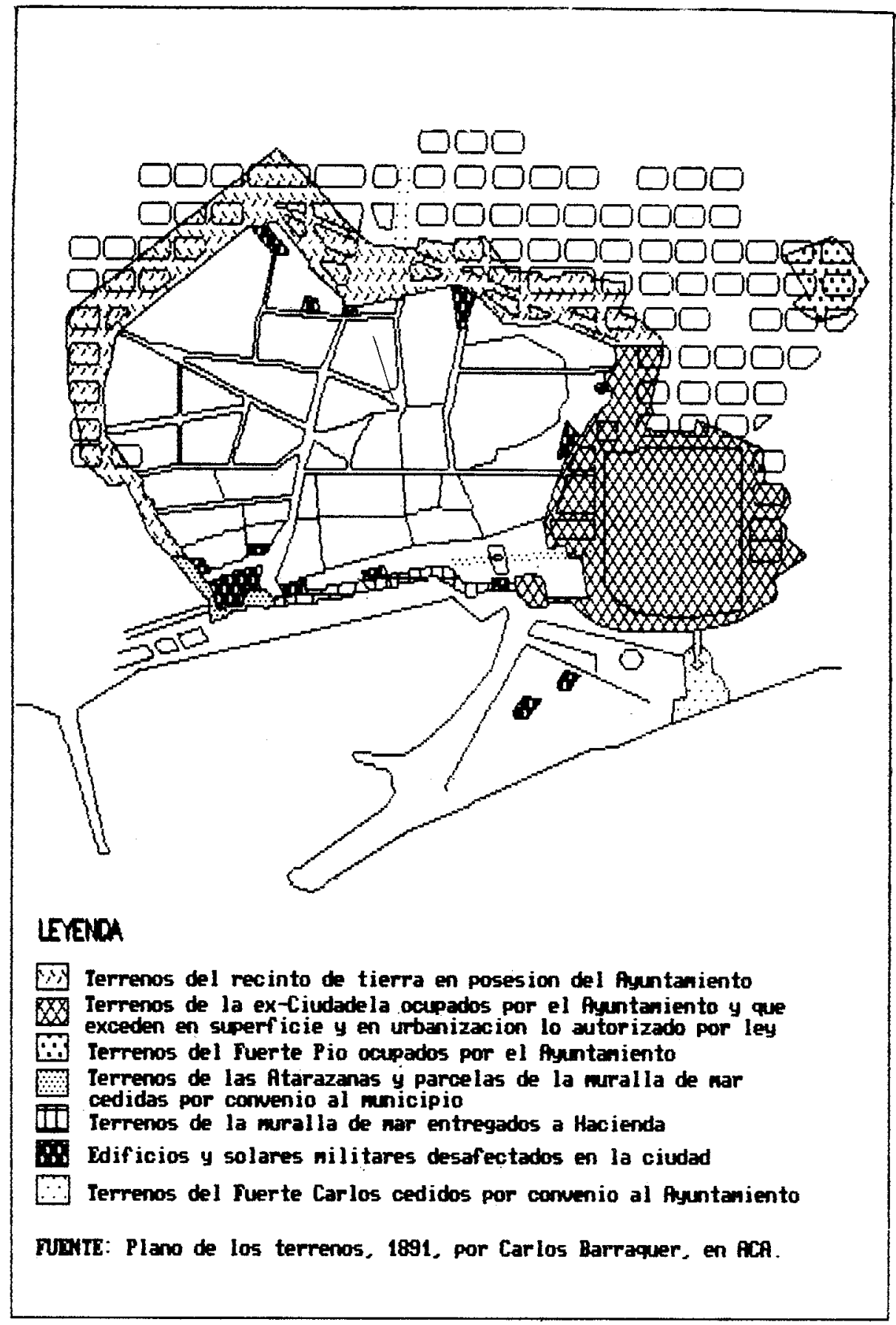

Fig. 1-Plano de los terrenos del Estado que usufructuó Guerra y pasaron a poder de la Hacienda Civil y del Municipio (Real Orden del Ministerio de la Guerra, 19 enero 1891). 
un censo de los solares de las derruidas murallas y su valoración económica a los precios de venta de los solares contiguos. Mas tarde llegarían las acciones judiciales y la conminación del Estado al Ayuntamiento a que cumpliera los compromisos convenidos $\left({ }^{17}\right)$.

La superficie del terreno enajenado ascendía a $240000 \mathrm{~m}^{2}$ y con un valor medio aproximado de 23000000 pts. en 1881 (18). $^{18}$. El primer acuerdo entre las instituciones involucradas hacía referencia al destino y transformación de la antigua Ciudadela, con más de $600000 \mathrm{~m}^{2}$. El compromiso inicial de construir los acuartelamientos necesarios fue substituido por otro convenio en el pago de 3500000 pts. en metálico, entregados efectivamente por el Ayuntamiento. Además el Estado debía percibir el uno y medio por ciento del valor del suelo dedicado a edificación en la zona. Una primera valoración en la década de los noventa hizo aumentar el valor de las murallas a 25000000 millones de pts. $\left(^{(19}\right)$. El Ayuntamiento acabó ocupando más del doble de los terrenos previstos en los anteriores acuerdos. En concreto, urbanizó $166000 \mathrm{~m}^{2}$ de $\operatorname{los}$ $53000 \mathrm{~m}^{2}$ previstos. Además la corporación municipal pagó al ministerio el valor de distintos fuertes exteriores $\mathrm{y}$ baluartes para la apertura de vías importantes del ensanche.

El resultado final de estas operaciones, transacciones y cambios de uso de unas estructuras y edificios obsoletos es difícil de valorar. A grandes rasgos, el municipio consiguió rentabilizar los hechos revolucionarios y definir el nuevo ensanche en base a los criterios del mercado inmobiliario. Era el fín de una larga etapa de intervención militar en el desarrollo urbano. En la administración del Estado, y concretamente para los militares quedó una conciencia de que podía aprovecharse mejor el conjunto de operaciones de desafectación de bienes del Estado.

«De lo expuesto y del plano que por duplicado se acompaña puede colejirse las grandes superficies de terreno en los

("i) Informe.., 1881, ACA, Caja 404; AdMINISTraciōN, 1880, ACA, Caja 404.

(18) Comandancia, 1881, ACA, Caja 404.

( $\left.{ }^{19}\right)$ Resolución..., 1891, ACA, Caja 404. Ministerio DE LA GUERRA, 1891, ACA, Caja 404. 
mejores emplazamientos de la ciudad que ha perdido el ramo de Guerra, la crecida suma de millones que representan, sobrada para dotar a Barcelona de cuantos edificios, campos de instrucción y demás servicios militares pudiera necesitar, para mejorar las defensas de Montjuich y construir baterias de costa que dejaran bien a cubierto la ciudad y puerto de todo insulto por mar, suma que ha dejado de percibir cuando tan evidente es el derecho que a ella tenía, segun demuestra el expediente remitido a informe y los antecedentes del asunto» $\left({ }^{20}\right)$.

Asimismo suponía el final de una etapa en la concepción estratégica de los entornos urbanos, enmarcándose en los límites de la nueva ciudad a construir, que como veremos volverá a engulir aquellas previsianes.

\section{Las Propiedades URbanas del Ministerio de Defensa EN EsPaña Y SU ENAJENACIÓN (1984-1990)}

Ahora vamos a realizar un corte en la explicación histórica $\mathrm{y}$ nos vamos a trasladar a períodos más cercanos en el tiempo, para analizar algunos de los elementos dinamizadores de la ciudad que tienen como protagonistas a las propiedades dependientes de las administraciones públicas. La valorización urbana implica el desarrollo de numerosos aspectos. La ordenación urbana puede también desarrollarse desde puntos de vista integradores del pasado con el sueño del futuro $\left({ }^{21}\right)$. El espacio se modela desde la política y a partir de elementos históricos que definen las características de la propiedad o la intervención del Estado en ese juego de intereses $\left.{ }^{(22}\right)$. La intervención estatal necesita todavía hoy de justificación en la esfera de una economía capitalista $\left({ }^{23}\right)$. Pero su importancia en términos de propiedad, por ejemplo, hace de aquella intervención un elemento a tener en cuenta. Los bienes públicos cuando son puestos al servicio de la generalidad parecen poco discutibles, puesto que en

${ }^{20}$ Comandancia, 1891, ACA, Caja 404.

(21) Valorizaৎ̧̃̃o..., 1990.

${ }^{(22)}$ LEFEVBRE, H., 1976.

${ }^{(23)}$ Fourquet, F. y Murard, L. M., 1978. 
principio no son provistos por el mercado $\left.{ }^{24}\right)$. La justificación es aún más necesaria cuando estos son desafectados institucionalmente, modificados, transferidos o incluso vendidos al sector privado. La puesta en el mercado de extensas propiedades públicas ha de generar inversiones que directamente o indirectamente ha sido utilizadas como instrumentos de política territorial ${ }^{25}$ ). Las intervenciones iniciadas en distintas ciudades españolas para revalorizar sus centros aún son puestas en cuestión por especialistas de distinto signo $\left({ }^{26}\right)$ e incluso aparecen como visiones optimistas desde las instituciones $\left({ }^{27}\right)$. De cualquier manera, la iniciativa oficial se ha visto incrementada estos últimos años, con las numerosas adquisiciones de propiedades y edificios sobresalientes, con un destino público en gran parte de los casos, aunque también han intervenido agentes privados. Sin embargo, todavía falta valorar los verdaderos efectos de esa acción pública, tanto en sus objetivos iniciales, como en los secundarios y más a largo plazo.

\section{Las infraestructuras y las propiedades militares}

Este apartado tiene como objetivo mostrar las características del proceso de desafectación de parte de las propiedades militares en el ámbito urbano español recientemente, desde el año 1984. En primer lugar, expondremos las razones y los motivos por los que ha sido posible reconvertir usos ya en decadencia dentro de las ciudades españolas. En segundo lugar, pretendemos mostrar las formas de ese proceso de desafectación de unos bienes propiedad del Estado y como estos han revertido en distintos proyectos, convenios y futuras revalorizaciones de amplias zonas urbanas. Por último, daremos algunos ejemplos de esta actuación positiva para las distintas estrategias en litigio, en concreto, para el caso de Madrid, Barcelona y Gerona. Entendemos que un análisis de este tipo puede ayudar a aclarar las distintas estrategias de elabora-

(24) FABO y BARINAGA, 1983.

(25) FABO y BARINAGA, 1983.

${ }^{\left({ }^{26}\right)}$ Espaces et sociétés, 1979; FERnández Alba, A. y Gavira, C., 1986; LóPez SÁNchez, P., 1986; NAVARRo SEgura, M. ISABEL, 1988.

${ }^{\left({ }^{27}\right)}$ Valorar la História, 1985. 
ción de posibles directrices para la transformación del suelo urbano a partir del cambio de uso de las infraestructuras detentadas por los grandes propietarios, obsoletas en muchos casos, y que pueden servir como dinamizadoras y valorizadoras de determinadas áreas de las ciudades.

El Ministerio de Defensa español inició en 1984 una política de venta de su patrimonio inmobiliario no imprescindible, para poder afrontar la compra de nuevos inmuebles. La valoración del patrimonio militar en España sobrepasa los 2 billones de pesetas, cifra todavía discutida dadas las dificultades de realizar un censo fidedigno. En cualquier caso, en España la extensión y valor del patrimonio militar sólo es comparable al de la Iglesia. Desde aquel año hasta 1989, el ministerio obtuvo ingresos superiores a los 16000 millones de ptas. y la superficie desprendida por el ministerio supera los $350000 \mathrm{~m}^{2}$ de suelo urbano y los $2000000 \mathrm{~m}^{2}$ de suelo rústico (1443 millones en 1984, 1647 en 1985, 2395 en 1986, 3041 en 1987, 12000 en 1988 y 14000 en 1989).

El organismo encargado de desarrolar esta política de compra-venta de inmuebles o de gestionar los excedentes inmobiliarios es la Gerencia de Infraestructura de la Defensa (GINDEF), creada en julio de 1984 por Ley. En el año 1990 el techo de su actuación quedaba enmarcado por la desafectación de $5400000 \mathrm{~m}^{2}$ de suelo urbano y $35500000 \mathrm{~m}^{2}$ de suelo rústico, lo que supone aproximadamente el $31 \%$ del patrimonio total del ministerio (cuadro 1). Para hacerse una idea de la escala de estas cifras, esta superficie suponde los $2 / 3$ de la provincia de Guipúzcoa.

\section{CUADRO 1}

Distribución de las propiedades del Estado afectas al Ministerio de Defensa en España (1986)

\begin{tabular}{l|c|c|c} 
Calificación propiedades & Núm. elementos & $\mathbf{M}^{2}$ inscritos & $M^{2}$ construidos \\
\cline { 2 - 4 } Rústico & 938 & 578917216 & 2560169 \\
Urbano & 1660 & 233276967 & 6255337 \\
Rústíco-Urbano & 14 & 21332659 & 292961 \\
Sin definir & 212 & 482224114 & 897125 \\
\hline Total & 2824 & 1315750966 & 10005592
\end{tabular}

Fuente: Ministerio de Defensa, Memoria.., 1986. 
Un censo acabado por la Secretaria de Estado de Infraestructura en 1990 proporciona una vision más ajustada de la importancia de estas cifras. Las propiedades de los tres ejércitos (tierra, marina y aire) suponen el $0,30 \%$ del territorio español, alcanzando una extensión de $1465470000 \mathrm{~m}^{2}$ (146 547 ha). De este conjunto mas de un tercio (49 $259 \mathrm{ha}$ ) tienen valor histórico-patrimonial por pertenecer a una herencia del siglo xIx. Otro tercio fue adquirido entre 1900 y 1960. El último tercio restante fue adquirido en los últimos 30 años. El periodo más activo fueron los años sesenta, aumentando su patrimonio en 25825 ha las propiedades, generalmente ligadas a grandes propiedades rústicas, fuera de los núcleos urbanizados $\left.{ }^{28}\right)$. Gran parte de este patrimonio está calificado como suelo rústico $\left(1311450000 \mathrm{~m}^{2}\right)$, mientras que el instalado en áreas urbanas es sensiblemente menor en extensión, que no en valor $\left(154020000 \mathrm{~m}^{2}\right)$. La corporación con mayor número de propiedades es el Ejército de Tierra con 109000 ha; el Ejército del Aire tiene 22600 ha y la Armada 11300 ha.

Los mecanismos de desafectación: una labor institucional de politica territorial

Con la organización de una institución militar autónoma para la gestión de las propiedades y recursos inmobiliarios el Estado ha dado un salto cualitativo en cuanto a los precedentes ya estudiados para el siglo xIX. La protección de bienes que resultan ser patrimonio del Estado pertenece al Ministerio de Economía y Hacienda y su desafectación entra dentro de lo que en términos jurídicos se denomina «actuaciones de iniciativa pública» $\left.{ }^{2 \theta}\right)$. Si hasta estos últimos años la postura militar ante el planeamiento puede ser definida como pasiva, desde la década de los ochenta podemos afirmar que comenzó una etapa de implicación directa en ella, para lograr una adecuada calificación del suelo y para gestionar autónomamente su riqueza patrimonial ${ }^{\left({ }^{30}\right)}$. Tal y como sucedió

(28) Soteras, ANA, 1991, El País, domingo 22 julio 1990.

(29) RODRIGUEZ-VILLASANTE, 1987.

${ }^{(00)}$ RODRIGUEZ-VILLASANTE, 1987. 
en el siglo pasado, el dominio público militar está ahora constituido por un conjunto de bienes excluidos del uso público por tener funciones muy limitadas a las características de la defensa. Así pues, las características de estos dominios son diversas: son del Estado pero no son de uso público y están estrictamente afectados a la defensa. Con estas características generales son productos inalienables, inembargables, o sea, no sujetos a comercio. Por lo tanto, precisan de una desafectación previa por parte de las autoridades militares, para poder colocarse en el mercado, $o$, en otras palabras, ejercer de agente social en la compra-venta de bienes. Si a esto añadimos una interpretación extensiva de la Ley del Suelo que permite la posibilidad de cesión y permuta a entidades públicas municipales o supramunicipales de terrenos con finalidades públicas completaremos el panorama intrincado que ha permitido la transformación y cambios de usos de amplios espacios en las ciudades españolas.

Todas estas características y figuras jurídicas pasaron a ser competencia exclusiva de la GINDEF en 1984, sucediendo en esta tarea a una institución mucho más limitada en atribuciones por abarcar solo las del Ejército de Tierra: la Junta Central de Acuartelamiento. El organismo autónomo, Gerencia de Infraestructura de la Defensa (GINDEF), dependiente del Ministerio de Defensa, cuenta en su Consejo Rector con representantes de los Ministerios de Economía y Hacienda, Obras Públicas e Urbanismo y Administración Territorial. En estos momentos debido a la extraordinaria revalorización de algunas ciudades resulta extremadamente valioso, aunque no estan ausentes los problemas, como la redifinición urbana de determinadas zonas o la polémica entre instituciones para decidir el destino final del patrimonio enajenado. La Ley 28/1984 de creación de la GINDEF estableció el carácter temporal de este organismo, no superior a 10 años. Con su organización las autoridades militares pretenden llevar a cabo la adecuación del patrimonio inmobiliario de Defensa a las nuevas necesidades, antes de 1995 , en que quedara disuelto dicho organismo. Sus funciones son las de desarrollar las directrices de Defensa en materia de patrimonio y condiciones urbanísticas, proponer modificaciones a los planes generales, 
colaborar con los ayuntamientos en los planes de ordenación urbana, así como comprar y vender bienes inmuebles.

Entre las formulaciones y criterios que originan su organización destacan un mejor aprovechamiento de los recursos disponibles, con una visión y programación economicista, poder contar con medios propios, que permitan una actuación más flexible de la Defensa en materia urbanística e inmobiliaria (basada en una reestructuración territorial de las FF.AA.) y, por último, la urgente necesidad de trasladar determinadas instalaciones militares fuera de los núcleos urbanos. El plan de modernización del Ejército de Tierra (Plan META) desarrollado entre 1983 y 1988 incluye entre sus objetivos el asentamiento de las grandes unidades en pocas bases. La autofinanciación de estas nuevas bases requiere desafectar patrimonio obsoleto, encerrado en los núcleos urbanos.

Una vez proyectada una nueva estructuración territorial, con la consiguiente supresión de algunas unidades y la creación de otras nuevas, $y$ siendo consciente la Administración del Estado de la urgente conveniencia de trasladar un bueno número de instalaciones fuera de los núcleos urbanos, se llevó a cabo una política negociadora con las Corporaciones Locales (Ayuntamientos) y Regionales (Comunidades Autónomas), que, a su vez, incluyeron algunas desideratas de las necesidades defensivas en la planificación urbanística ${ }^{(31}$ ). Esta Gerencia, cuyo Reglamento fue aprobado por Real Decreto $2698 / 1985$ de 27 de diciembre, desarrolla las directrices que, en materia de patrimonio, dicta el Ministerio acerca de los planes de infraestructura de las FF.AA. y, principalmente, adquiere los bienes inmuebles con destino al dominio público del Estado para su afectación a los fines de la Defensa, enajenando aquellos otros que dejan de ser necesarios a dichos fines. Con estas enajenaciones la administración militar obticne una fuente de ingresos para dotaciones, sin aumentar las necessidades ya adquiridas, incluso reduciéndolas, al disminuir los gastos derivados del mantenimiento de instalaciones que dejan de tener utilidad a efectos militares.

La Gerencia de Infraestructura (GINDEF) ha concertado con las respectivas Corporaciones Locales las condiciones eco-

(31) MINisterio DE DEFENSA, 1989. 
nómicas y urbanísticas que permitan la instalación de los acuartelamientos en aquellas zonas que, atendiendo las necesidades del Ministerio, no incidan negativamente en los planteamientos urbanísticos. Los convenios pueden afectar a un sólo inmueble $o$, con más frecuencia, a un conjunto de ellos 'y, en cualquier caso, permiten el empleo de antiguas instalaciones, algunas de ellas de carácter histórico-artístico, y muy ligadas a la historia urbana, pero cuya funcionalidad militar ha quedado obsoleta. En los convenios urbanísticos con instituciones regionales o locales se negocian los términos de cesión, venta o permuta de las enajenaciones, de las propiedades puestas a disposicion de otras entidades del Estado. Hasta el año 1990 la GINDEF ha firmado más de 50 convenios (fig. 2) con distintas instituciones, en su mayoria municipales $\left(^{32}\right)$.

La enajenación de los bienes de dominio público (Propiedades del Estado) se ha realizado de distintas maneras y formas jurídicas. Entre éstas hay que destacar la venta directa, la permuta o una figura intermedia formulada a partir de grandes convenios. La Ley reguladora de la GINDEF $\left(^{33}\right)$ establece un tipo de enajenación «onerosa», sin que puedan cederse los bienes gratuitamente a ninguna persona física, jurídica, pública o privada, salvo las cesiones contempladas en la legislación urbanística. Las ventas deben llevarse a cabo por pública subasta, aunque puedan enajenarse directamente bienes inmuebles tanto a particulares como a Comunidades Autónomas o Corporaciones Locales, aprobadas por el Gobierno, previa comunicación al Ministerio de Economía y Hacienda. En el caso de la venta libre, la adjudicación se efectua al mejor postor, con determinadas condiciones $y$ requisitos $\left({ }^{34}\right)$.

Un proyecto global de renovación urbana para la capital del Estado

Son numerosos los ejemplos que podriamos escoger para representar todo este proceso que venimos explicando. Vamos

(22) MiNisterio DE DEFEN.SA, 1989.

( $\left.{ }^{33}\right)$ Boletín Oficial del Estado núm. 183, 1 Agosto 1984, pp. 22341-2.

( $\left.{ }^{34}\right)$ Real Decreto 2698/1985, 27 de diciembre, Boletín Oficial del Estado núm. 45, 21 de febrero 1986, pp. 6767-69. 


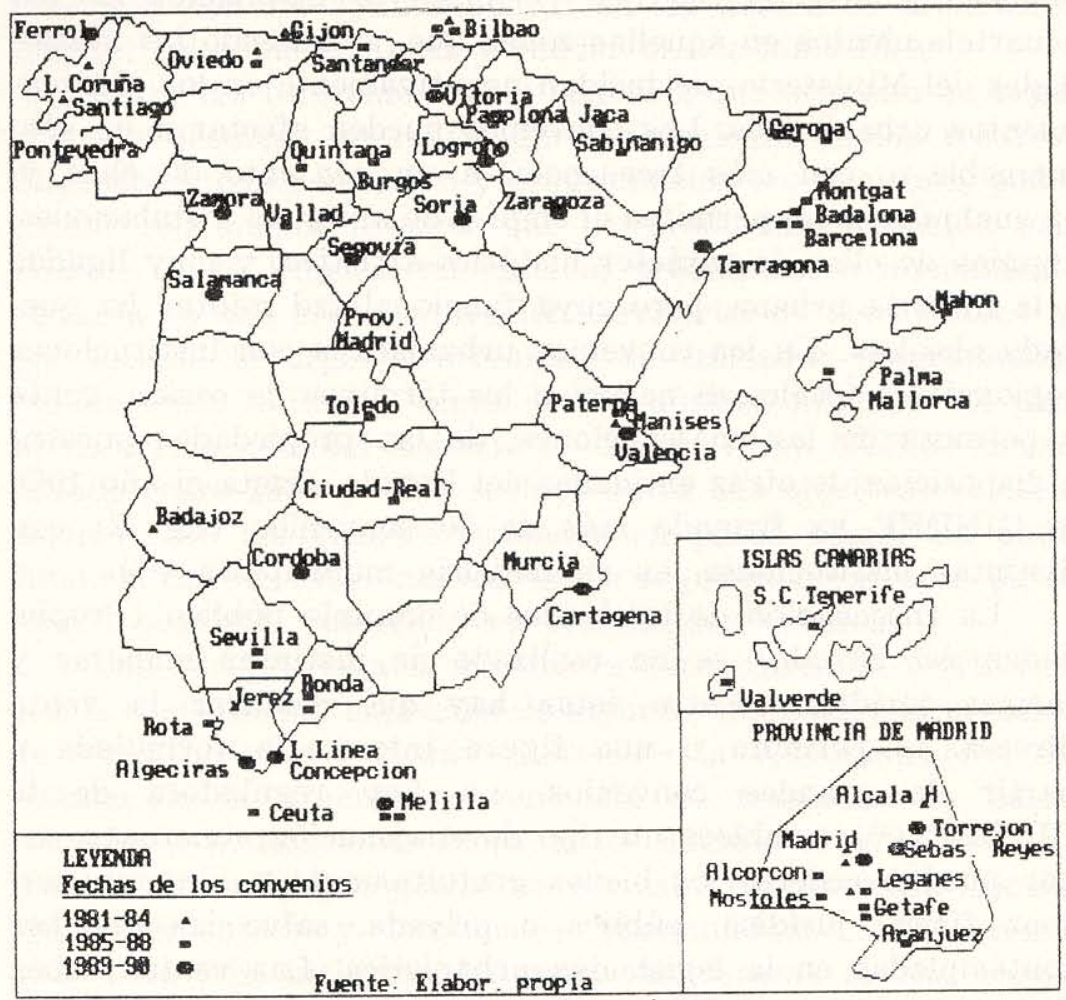

Fig. 2-Municipios afectados por convenios con el Ministerio de Defensa (1981-1990).

a ceñirmos a tres casos con desarrollos y consecuencias distintos, a pesar de haberse utilizado similar métodología, en forma de convenios con instituciones municipales. En primer lugar mostraremos un ambicioso proyecto para la modificación de los usos de propiedades militares en Madrid. A continuación reseñaremos la trascendencia de las desafectaciones militares en la ciudad de Barcelona. Y por último acabaremos este largo artículo con las implicaciones urbanísticas para el caso de la ciudad de Gerona.

El caso de Madrid tiene un especial interés por ser la capital del Estado, por el número de instalaciones implicadas en el proceso de enajenación y por ser en cierta manera una excepción fallida si tenemos en cuenta los objectivos iniciales. 
Durante el siglo xIx la presencia militar en Madrid no era mucho más relevante que la de una ciudad como Barcelona. Después de la Guerra Civil (1936-1939) esta aumentó sensiblemente. En nuestros días estas instalaciones se encuentran en dos anillos paralelos (fig. 3). Uno situado en lo que en la posguerra era todavía el extrarradio urbano, hoy plenamente integrado (Carretera de Extremadura y otros). El otro situado en los pueblos del área metropolitana. A estos hay que añadir un conjunto de instalaciones administrativas $y$ educativas situadas en el centro de la ciudad, dependientes de la administración militar.

Desde el año 1981 el Ayuntamiento de Madrid negociaba con la Junta Central de Acuartelamiento para conseguir suelo y terrenos de propiedad militar, con el objeto de obtener equipamentos colectivos. En forma de convenio firmado ese mismo año permite además al Ministerio de Defensa ampliar su patrimonio en viviendas militares y revertir ciertas propiedades a suelo urbanizable. Estas negociaciones estuvieron presididas por la elaboración y redacción final del Plan General de Ordenación Urbana de Madrid. El gran proyecto de unos años más tarde fue considerado inviable por la dificultad efectiva de trasladar las grandes unidades de la capital.

Unos años más tarde, en 1986, nuevamente las instituciones citadas, junto a otros municipios metropolitanos llegan a acuerdos para reducir el número de instalaciones militares. Los términos generales de los acuerdos destacan el valor para las ciudades de la recuperación de esas infraestructuras, a cambio de cesión de otros terrenos alejados de los cascos urbanos $\mathrm{y}$ facilidades para edificar viviendas estrictamente militares. En estos años se unen a esta filosofía los municipios de Getafe, Móstoles, Leganés y Torrejón de Ardoz. Mientras tanto, algunos edificios militares reconvierten sus usos. Em 1985 el ministerio de Defensa cede un cuartel para la ampliación del Senado, y en 1987 otro se convierte en un gran conservatorio, en 1988 un palacio anexo al Museo del Ejército pasa a las dependencias del Museo del Prado.

Tras estas experiencias, durante el año 1988 surgirán otras más globales, que definirán el gran proyecto denominado de Campamento. Algunas fuerzas políticas proponen ya entonces, desde el foro de la Comunidad de Madrid le reconversión de 


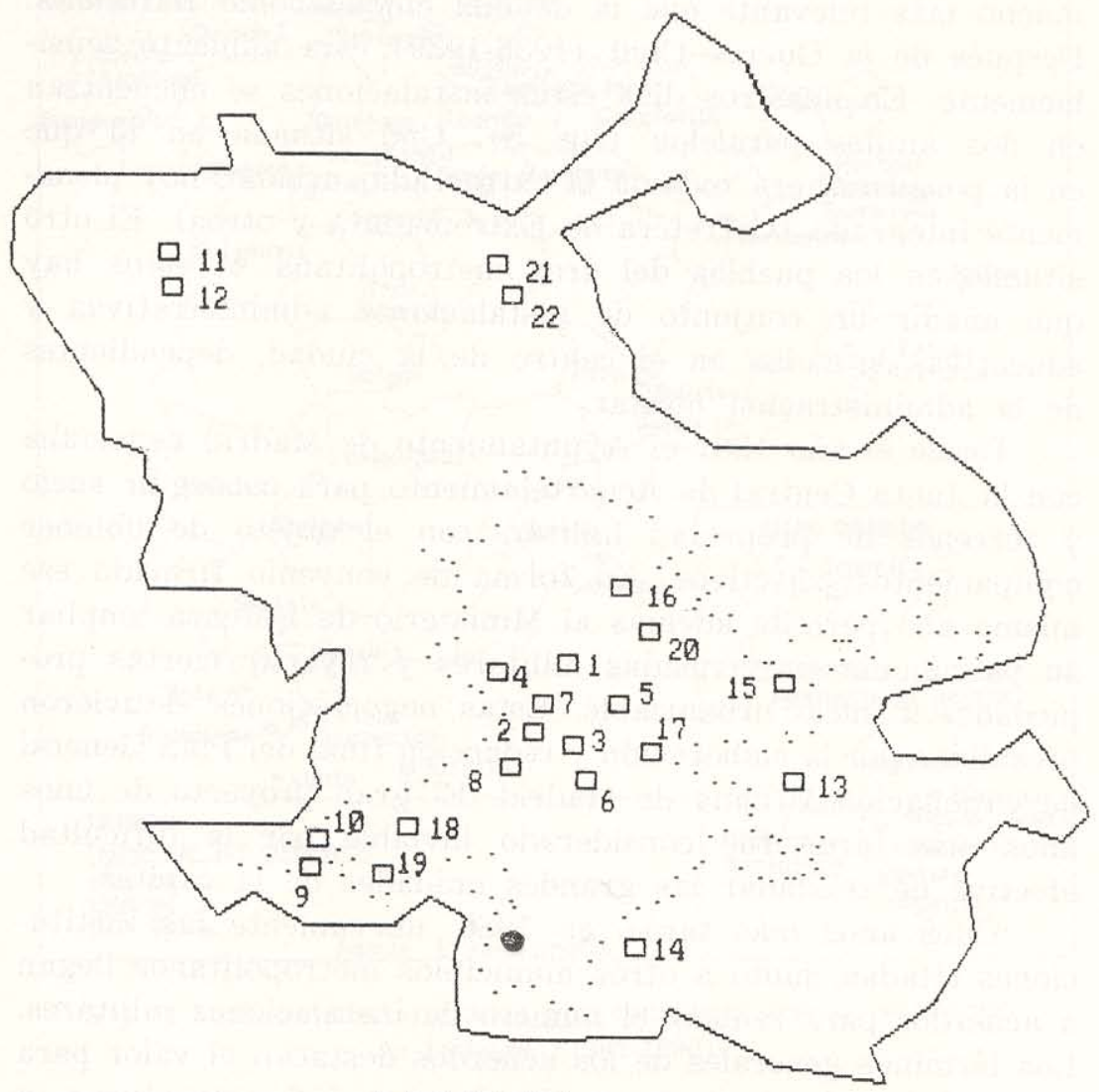

LEYENDA

Casco urbano

Termino Municipal

1. Ministerio Defensa

2. Cuartel Cen. Ejercito

3. Cuarlel Cen. Armada

4. Cuartel Cen. Aire

5. CESID

6. Agrup. Encuadramiento

7. Escuela Sup. Guerra

8. Cobierno Militar

9. Aerodromo Cuatro Vientos

10. Complejo Mil. Carret. Extremadura
11. Cuarlel Transmisiones

12. Division Acorazada

13. Regim. Arfilleria

14. Parque Automouil.

15. Reg. Aufomovil.

16. Cuartel Inf. Marina

17. Almacen Intendencia

18. Parque Sanidad Militar

19. Hospital Militar.

20. Hospital Cen. Aire

21. Brigada Acor azada

22. Reg. Inf. Mecanizada

FUENTE: El Pais, 1988 y elabor. propia

Fig. 3 - Madrid. Principales instalaciones militares (1988). 
los cuarteles en centros culturales y zonas verdes. Esta institución está dispuesta a colaborar en la organización de la descentralización universitária, aprovechando precisamente las propiedades militares. Con estos precedentes, durante el verano del año 1988, la Comunidad de Madrid elabora un plan para el uso civil del complejo militar de Campamento, en un momento en que la GINDEF y el Ayuntamiento de Madrid estaban llegando a acuerdos para desmantelar las instalaciones militares de esa zona en un período razonable de tiempo. El objetivo inicial era convertir esta extensa zona de Madrid en una miniciudad, «sin coste para el contribuyente».

En convenio firmado casi un año después, en 1989, recogía una serie de contrapartidas mutuas entre tres instituciones, el Ministerio de Defensa, la Comunidad de Madrid y el propio Ayuntamiento, aunque este último solo se adhirió al documento, quizás preveyendo su rechazo en el difícil equilibrio del consistorio en esos momentos. La Zona Militar de Campamento abarca una extensión de casi $8000000 \mathrm{~m}^{2}$, con seis acuartelamientos y 11 unidades, una cuarta parte de las instalaciones militares en la ciudad, y donde existe suelo suficiente para construir más de 30000 viviendas de protección oficial. A cambio de la gestión de ese planeamiento el Ministerio de Defensa pensaba obtener una parte de la nueva edificabilidad disponible, superando así el techo del Plan General de Ordenación Urbana, en esos momentos en fase de revisión, y una cantidad que osciló cercana a los 30000 millones pts.

Con esta actuación se iban a utilizar $2000000 \mathrm{~m}^{2}$ para viviendas $\mathrm{y}$ oficinas $\left(1200000 \mathrm{~m}^{2}\right.$ para oficinas, $500000 \mathrm{~m}^{2}$ para viviendas y $300000 \mathrm{~m}^{2}$ para equipamientos comerciales), desdoblar la carretera de Extremadura, prolongar una linea de metropolitano, la recuperación de centros civicos, la reordenación de la Casa de Campo y por ultimo la construcción de un nuevo campus universitario de la Politécnica madrileña. El costo estimado de esa reconversión supondría un valor de 300000 millones de pts. de la época. Toda esta vasta área quedaría liberada de sus usos militares para dar paso a una ciudad dentro de la capital. El objetivo de los planificadores era construir un proyecto donde tuviera cabida un gran centro de atracción, equilibrador del centro urbano tradicional, asociando usos residenciales y comerciales. 
Otros proyectos relacionados con el anterior aparecieron en el mismo período. Este es el caso del Parque de Ingenieros de Villaverde, con una extensión superior a los $250000 \mathrm{~m}^{2}$ de extensión, con grandes espacios libres y muy poca actividad militar. El reparto previsto en el plan o convenio era el siguiente: $131000 \mathrm{~m}^{2}$ de utilización para viales, $65000 \mathrm{~m}^{2}$ para parque público, $48000 \mathrm{~m}^{2}$ para futuras instalaciones deportivas y culturales y $31356 \mathrm{~m}^{2}$ para la construcción de 750 viviendas de protección oficial. Este proyecto fue muy contestado en ese período pues suponía la recalificación del suelo de otros inmuebles militares para ser vendidos en subasta.

Estos convenios fueron anulados por la nueva administración municipal solo 15 días después de su firma. Los razonamientos empleados para tal decisión pasaron por considerar que modificaba el Plan General y por ser un proyecto más de la Región Autónoma que del municipio.

Después de este proyecto de actuación, la GINDEF inició una nueva estrategia de la desafectación de las propiedades militares, esencialmente la venta directa por subasta. Ese es el proceso empleado en diversos casos en todo el país (cuadro 2), como el cuartel Daoiz y Velarde (Atocha), vendido a una Cooperativa de construcción por más de 2000 millones pts., como un solar $\left(92000 \mathrm{~m}^{2}\right)$ vendido a una institución financiera (Caja de Madrid) por 7400 millones de pts. En ambos casos, los usos futuros están ligados al mercado inmobiliario en una zona como la carretera de Barcelona.

La necesidad de equipamentos para una ciudad saturada. El Convenio entre el Ayuntamiento de Barcelona y la GINDEF

El convenio firmado en 1988 por el Ayuntamiento de Barcelona $y$ la GINDEF contiene dos partes fundamentales. En la primera se exponen las fincas e inmuebles puestas a disposición de la ciudad por la Administración Militar (cuadro 2) y el propio Ayuntamiento, junto a una justificación de los motivos. En otro apartado se establecen los términos y claúsulas del convenio de compra-venta, con las fechas de pago, entrega de propiedades en diferentes fases y las comisiones de seguimiento del convenio. 
CUADRO 2

Ejemplos de grandes desafectaciones de propiedades militares en España

\begin{tabular}{|c|c|c|c|c|c|c|c|}
\hline Municipios & Año & $\begin{array}{c}\text { Edificios } \\
\text { y zonas }\end{array}$ & $\begin{array}{l}\text { Modalidad } \\
\text { adoptada }\end{array}$ & $\begin{array}{l}\text { Institución } \\
\text { impliceda }\end{array}$ & $\begin{array}{l}\text { Precio } \\
\text { mll/pts }\end{array}$ & $\begin{array}{l}\text { Usos } \\
\text { futur. }\end{array}$ & $\begin{array}{l}\text { Super. } \\
\mathbf{m}^{2}\end{array}$ \\
\hline Barcelona & 1986 & Edificio & Subasta & Privado & 2000 & Cen. Com. & \\
\hline Barcelona & 1987 & Cuartel & Convenio & Adm. Pub. & 314 & Trib. & 13899 \\
\hline Barcelona & 1987 & Cuartel & Convenio & Municipal & 129 & Equip. & 4205 \\
\hline Barcelona & 1987 & Cuartel & Convenio & Municipal & 665 & Equip. & 53175 \\
\hline Barcelona & 1987 & Cuartel & Convenio & Municipal & 337 & Univ. & 13499 \\
\hline Barcelona & 1987 & Almacen & Convenio & Municipal & 124 & & 8570 \\
\hline Barcelona & 1987 & Parque & Convenio & Municipal & 67 & Educ. & 6218 \\
\hline Barcelona & 1989 & Residenc. & Convenio & Priv.-Mun. & 3625 & Hotel & 6158 \\
\hline Barcelona & 1989 & Comand. & Subasta & Privado & 80 & & 702 \\
\hline Barcelona & 1990 & Terrenos & Convenio & Adm. Pub. & 5 & & 11332 \\
\hline Madrid & 1991 & Terrenos & Convenio & Adm. Pub. & & Equip. & \\
\hline Madrid & 1985 & Cuartel & Cesió & Adm. Pub. & & Senado & \\
\hline Madrid & 1987 & Cuartel & Cesió & Adm. Pub. & & Conserv. & \\
\hline Madrid & 1988 & Terrenos & Subasta & Privado & 6600 & Viviend. & \\
\hline Madrid & 1988 & Museo & Cesion & Adm. Pub. & & Mueso & \\
\hline Madrid & 1989 & Parque & Convenio & Adm. Pub. & & $\begin{array}{l}\text { Equip. } \\
\text { Vicien. }\end{array}$ & 250000 \\
\hline Madrid & 1989 & Unidad. & Convenio & Adm. Pub. & 30000 & $\begin{array}{l}\text { Equip. } \\
\text { Vivien. }\end{array}$ & 3000000 \\
\hline Madrid & 1991 & Solar & Subasta & Privado & 7400 & $\begin{array}{l}\text { Vivien. } \\
\text { Hotel }\end{array}$ & 92000 \\
\hline Madrid & 1991 & Cuartel & Convenio & Adm. Pub. & 17000 & Equip. & 25000 \\
\hline Gerona & 1985 & Edificio & Convenio & Municipal & & & 17800 \\
\hline Gerona & 1985 & Cuarteles & Convenio & Municipal & 600 & Equip. & 105408 \\
\hline Gerona & 1989 & Fortific. & Subasta & Privado & 47 & & 10170.5 \\
\hline Alcorcón & 1987 & Cuartel & Subasta & Privado & & Vivien. & \\
\hline Cáđiz & 1989 & Cuartel & Convenio & Municipal & & & \\
\hline Cartagena & 1988 & Edificio & & & 81 & & \\
\hline Cartagena & 1988 & Edificio & & & 48 & & \\
\hline Cordoba & 1990 & Cuarteles & Convenio & Municipal & & & \\
\hline Getafe & 1986 & Cuartel & Cesión & Municipal & & & \\
\hline Getafe & 1989 & Edificios & Convenio & Adm. Pub. & & Univers. & \\
\hline La Coruña & 1988 & Cuartel & Convenio & Municipal & 808 & Vivien. & \\
\hline Leganes & 1990 & Cuartel & Convenio & Adm. Pub. & & Univer. & \\
\hline Orense & 1990 & Cuartel & Conv./sub & Mui/Priv. & & Hotel & 140.00 \\
\hline Malaga & 1989 & Terrenos & Conven:o & Municipal & & Turism. & \\
\hline Oviedo & 1936 & Cuartel & Convenio & Adm. Pub. & & Univers. & \\
\hline Pamplona & 1984 & Murallas & Convenio & Municipal & & Zon. ver. & \\
\hline Rcnda & 1985 & Terrenos & Convenio & Municipio & & & \\
\hline Rota & 1989 & Residencia & Subasta & Privado & 275 & & \\
\hline Rota & 1988 & Terrenos & Subasta & Privado & 99 & & \\
\hline Santiago & 1988 & Cuartel & Convenio & Pub./Priv. & 2205 & $\begin{array}{l}\text { Parlam. } \\
\text { Viviend. }\end{array}$ & \\
\hline Toledo & 1989 & Alcazar & Cesión & Adm. pub. & & Bibliot. & \\
\hline Valladolid & 1989 & Terrenos & Convenio & Municipal & & & \\
\hline Zamora & 1990 & Cuartel & Convenio & Adm. pub. & & Univers. & \\
\hline
\end{tabular}

Fuente: GINDEF y elaboración propia. 


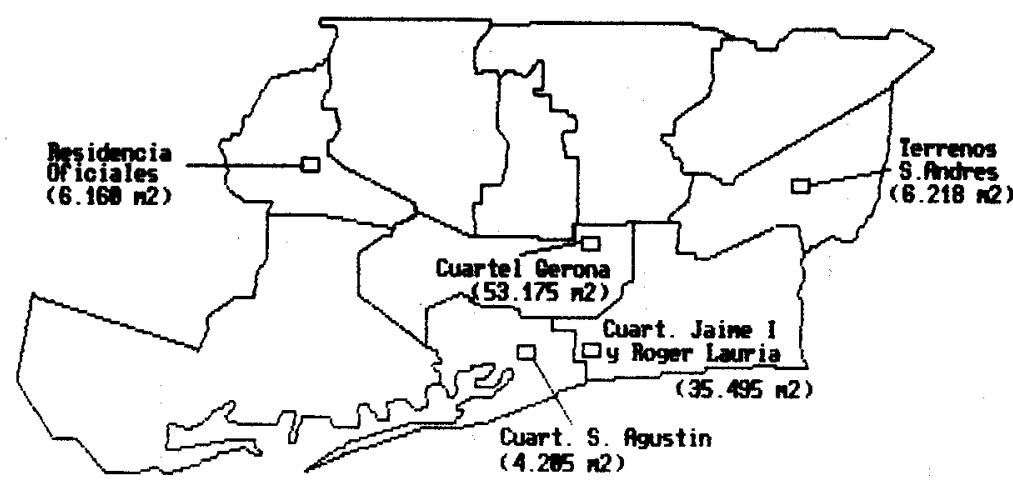

Novit: Elaborac. propia

Fig. 4-Localización de las propiedades enajenadas en la ciudad de Barcelona.

\section{CUADRO 3}

Propiedades militares entregadas al Ayuntamiento de Barcelona por convenio (1988)

\begin{tabular}{|c|c|c|c|}
\hline Edificios & $\begin{array}{c}\text { Suelo } \\
\left(\text { en } \mathrm{m}^{2}\right)\end{array}$ & $\begin{array}{l}\text { Suelo edif, } \\
\left(\mathrm{en}^{2} \mathrm{~m}^{2}\right)\end{array}$ & Anteriores usos \\
\hline Cuartel San Agustin & 4025 & 9884 & Farmacia mil. \\
\hline Pabell. Tantaranı́ana & 290 & 1453 & Viviendas mil. \\
\hline Sclar San Andres & 6218 & & Parque Artill. \\
\hline Cuartel Gerona & 34136 & 28.011 & Reg. Caball. \\
\hline Cuartel Jaime I & 11408 & 21072 & Intendencia \\
\hline Cuart. Roger Lauria & 8375 & 22378 & Almacen Int. \\
\hline Pabell. Wellington & 6.450 & 25800 & Resid. mils. \\
\hline Total & 72011 & 108598 & \\
\hline
\end{tabular}

Fuente: Convenio Ayuntamiento Barcelona-Gerencia Infraestrutura, 1991.

El documento contiene, además, unos Anexos sobre las características físicas y jurídicas de las propiedades. Finalmente, el convenio de Barcelona afectó a un conjunto de 7 propiedades militares que ocupan $72011 \mathrm{~m}^{2}$ de suelo urbano $\mathrm{y}$ 
$108598 \mathrm{~m}^{2}$ edificados, incluyendo 140 viviendas militares, todavía no desafectadas. Su localización es de gran interés para el proceso de renovación urbana de una amplia área localizada en el frente costero barcelonés. Por su parte, el Ayuntamiento enajena una finca anexa al actual edificio de la Capitanía General, antiguo Convento de la Merced, de una extensión superficial de $568 \mathrm{~m}^{2}$ y de $2841 \mathrm{~m}^{2}$ de edificación.

El convenio entre el Ayuntamiento de Barcelona y la GINDEF tuvo como objetivo proporcionar suelo urbano $y$ equipamientos al Ayuntamiento, en el marco de los JJ.OO. de 1992, cediendo instalaciones, que se encuentran en emplazamientos poco adecuados para su función. Las clausulas más importantes hacen referencia a las contraprestaciones económicas y sistemas de pago. El monto total asciende a 1640 millones de ptas., a satisfacer en 4 años. La transmisión de las fincas debe efectuarse libre de cargas y gravámenes, y en dos fases: una a la firma del convenio y otra transcurrido un año. Otro aspecto importante de este convenio fue la calificación urbanística. Cualquier modificación de los términos del convenio debe contar con la conformidad del Ministerio y las transmisiones futuras sólo son posibles a instituciones públicas, con derecho de retracto por parte de las autoridades militares si se hicieran a particulares.

Las transformaciones en los usos de estas propiedades han sido diversas. En general estan centralizados en los equipamientos, municipales, de la administración de justicia y educativos. Los beneficiarios de estas transformaciones han sido las áreas concretas donde estaban ubicados, en gran medida deficitarias.

Con independencia de este convenio el ministerio de Defensa ha tenido otras actuaciones en la ciudad de Barcelona, con el objetivo de descentralizar el despliegue de las tropas en Cataluña, trasladando las unidades a la zona pirenaica (cuadro 2).

El ordenamiento urbanistico y las propiedades militares en Gerona (1985)

Este convenio fue uno de los primeros en concretizarse en el año 1985, y contiene algunas variaciones con el de Bar- 
celona. Su objeto explícito era facilitar los planes de infraestructura del Ministerio de Defensa, haciendo compatibles las necesidades de las FF.AA. con el planeamiento urbanístico municipal y «permitiendo la realización de la edificación otorgada en el nuevo ordenamiento urbanístico» $\left({ }^{35}\right)$.

Asimismo permitió al Ayuntamiento la obtención de suelo con destino a espacios libres, de uso público, equipamientos comunitarios y viarios en zona urbana deficitaria, en relación con la densidad de población futura, y conseguir edificios de interés patrimonial en el centro histórico, revitalizándolo con otros usos. En su conjunto, el convenio de Gerona, afectó al antiguo convento de Sto. Domingo, convento del siglo xIII, desamortizado en el siglo xIx y en 1846 destinado a finalidades militares, con $17800 \mathrm{~m}^{2}$ de suelo y 3324 de edificación, sede del Gobierno Militar, y a unos amplios terrenos, conjunto de cuarteles de construcción reciente y otros edificios del ensanche de la ciudad, con una extensión superficial de $105408 \mathrm{~m}^{2}$ (cuadro 4 y fig. 5).

En el caso de Gerona, también fueron distintos los criterios de valoración de las propiedades. La solución adoptada fue partir de la repercusión del precio de venta por $\mathrm{m}^{2} \mathrm{de}$ edificación y del coste de urbanización. En el indice resultante entraban tanto los valores comerciales como el rendimiento del suelo derivado de la ordenación urbana. El acuerdo debía etnrar en vigor una vez aprobado el planeamiento urbanístico y cuando las FF.AA. pudieran trasladar sus efectivos. Por su parte, el Ayuntamiento se comprometía a entregar 100 millones ptas. en tres anualidades, permitir en su Plan General de Ordenación Urbana una zona de equipamiento sin limitaciones de uso, y con una edificabilidad total de $14825 \mathrm{~m}^{2}$, más $60000 \mathrm{~m}^{2}$ de trecho residencial para Defensa. Finalmente, como en situaciones ya señaladas aquí, en caso de que el planeamiento urbanístico de Gerona no cumpliese con estas condiciones el Ministerio de Defensa se reserva el derecho de recuperar todos o parte de los terrenos desafectados en el convenio. 


\section{CUADRO 4}

Inventario de las propiedades enajenadas por la GINDEF en las ciudades de Barcelona y Gerona (1985-1990)

\begin{tabular}{|c|c|c|c|}
\hline Barcelona/Edificios & $\begin{array}{c}\text { Superfície } \\
\text { (en } \mathrm{m}^{2} \text { suelo) }\end{array}$ & $\begin{array}{l}\text { Valoración } \\
\text { (en ptas.) }\end{array}$ & Enajenación \\
\hline Cuartel Roger Lauria & 13899 & 314880000 & DIRECTA \\
\hline Cuartel San Agustin & 4205 & $1,29560: 000$ & DIRECTA \\
\hline Cuartel Gerona & 53175 & 665840000 & DIRECTA \\
\hline Parcela Aeropuerto & 2500 & 2500000 & AFECTA \\
\hline Parcela Aeropuerto & 2500 & 2500000 & SUBASTA \\
\hline Parque Artilleria & 6218 & 67500000 & DIRECTA \\
\hline Pabells. Tantarantana & 290 & & DIRECTA \\
\hline Terrenos Wellington & 9086 & & DIRECTA \\
\hline Talleres Intendencia & 8570 & 124640,000 & DIRECTA \\
\hline Parcela Aeropuerto & 2500 & 2500000 & DIRECTA \\
\hline Cuartel Jaime I & 13499 & 337580000 & \\
\hline Residencia Oficiales & 6158 & 3625000000 & \\
\hline Comandancia Somatenes & 702 & 80.436875 & \\
\hline Parcela Puerto & 536 & 8000000 & DIRECTA \\
\hline Terrenos Hospital Mil. & 11332 & 5000000 & \\
\hline Total & 135170 & 5365936000 & \\
\hline Gerona/Edificios & $\begin{array}{c}\text { Superfície } \\
\left.\text { (en } \mathrm{m}^{2} \text { suelo }\right)\end{array}$ & $\begin{array}{l}\text { Valoración } \\
\text { (en pts.) }\end{array}$ & Enajenación \\
\hline Gobierno Militar & 17800 & & \\
\hline Sector Cuarteles & 105408 & $600: 000,000$ & DIRECTA \\
\hline Fuerte S. Julia Ramis & 101705 & 74.600000 & SUBASTA \\
\hline Total & 224913 & 647600000 & \\
\hline
\end{tabular}

Fuente: Gerencia, 1991.

\section{ConClusiones}

La colaboración entre las instituciones del Estado español ha hecho posible realizar los intereses de éstas, aunque sean distintas en su concepción. Por un lado, el Ministerio de Defensa ha conseguido obtener financiación para reorganizar territorialmente las FF.AA. y, por otro, otras instituciones centrales, regionales o locales han obtenido suelo urbano, de gran interés para la revitalización de los centros históricos o de 


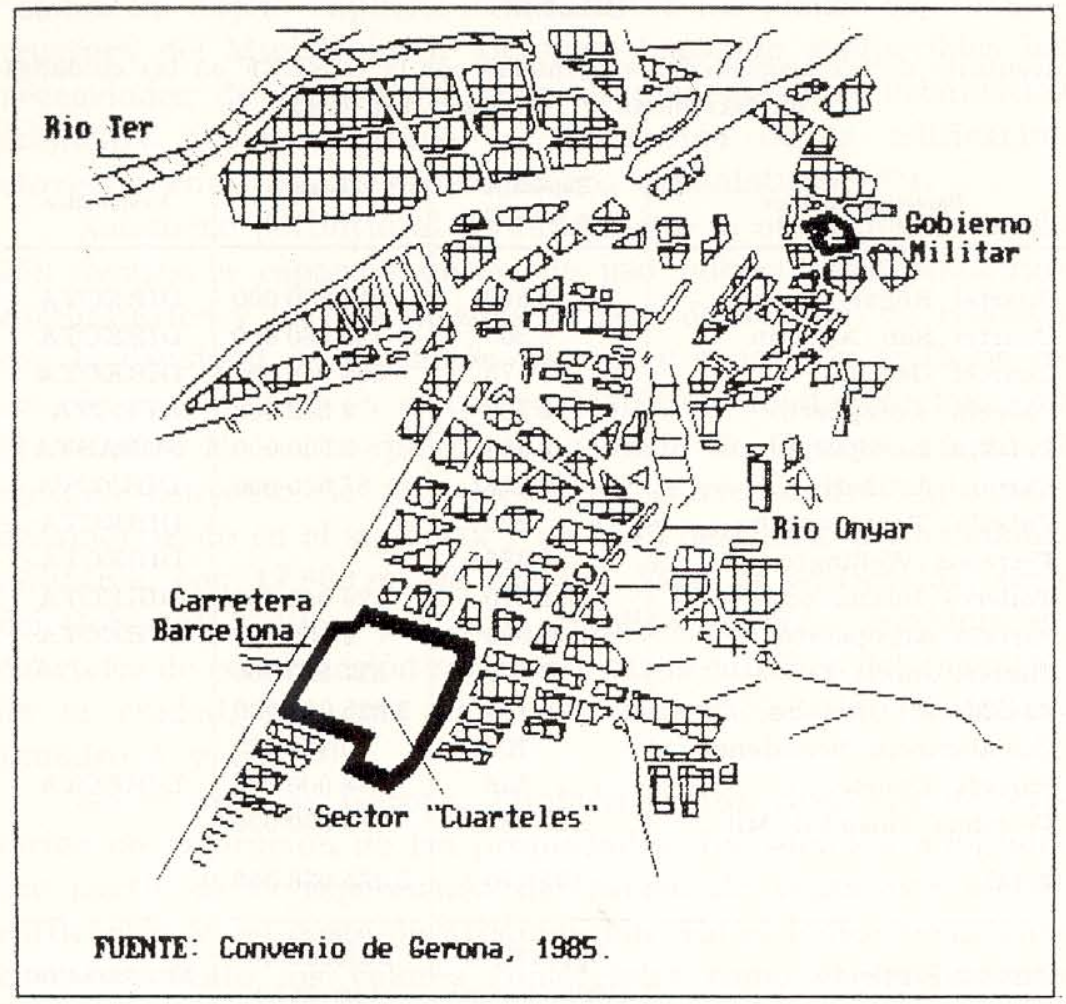

Fig. 5-Gerona. Situación de las propiedades militares enajenadas.

amplias zonas de las ciudades. Tampoco puede obviarse que este proceso de desafectación de grandes propiedades militares en el espacio urbano ha tenido problemas, derivados de las distintas posiciones negociadoras y solucionados de forma individual, con criterios, en muchos casos, alejados. En el fondo de estos problemas hay que ver las dificultades de las haciendas locales, la capacidad de transformación y renovación urbanística de las ciudades, y, por último, la voluntad de colaboración de la administración política-militar para conseguir que la renovación de sus infraestructuras tenga un apoyo en la ciudadanía. 


\section{BIBLIOGRAFIA}

Administracion Eoonomica de ta Provincia de Barceiona. Negociado de Propiedades y Derechos del Estado, Relación de los solares procedentes de las derruidas murallas de esta capital que han sido enajenados por el Estado, manzanas a que corresponden, su cabida $y$ valor, Barcelona 13 dictembre 1880, ACA, Caja 404.

AJUNTAMENT DE BARCELONA, El Quadrat d'Or, Barcelona, 1990.

BASSEGODA MUSTE, «Urbanismo poliorctico», en Memorias de la Academia de Ciencias y Artes de Barcelona, Tomo XXVII, núm. 14, 1945, pp. 483-522.

BOSCH Y ARROYO, M., Zonas militares. Consideraciones sobre estas servidumbres, Madrid, Imp. Memorial de Ingenieros, 1881, $132 \mathrm{pp.}$

CAPEL, H., Geografía y Matemáticas en la España del siglo XVIII, Vilassar de Mar, Oikos-Tau, 1982, 398 pp.

CAPEL, H., SANCHez, J.-E. y MoncadA, O., De Palas a Minerva. La formación cientifica y la estructura institucional de los ingenieros militares en el siglo XVIII, Barcelona, Ed. del Serbal y CSIC, $1988,390 \mathrm{pp}$.

COMANDANCIA DE INGENIEROS, Informando acerca de los derechos que tiene el ramo de Guerra a los terrenos de la muralla de Mar, 21 de marzo de 1878, Archivo de la Corona de Aragón, Fondo Comand. Ing., Exp. 2646.

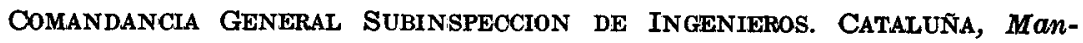
dando se informe acerca de los derechos que tiene el ramo de guerra a los terrenos de la muralla de Mar, 14 de marzo de 1878, Archivo de la Corona de Aragón, Fondo Comand. Ing., Caja 404.



COMANDANCIA DE BARCELONA, Valoración de los terrenos procedentes de las derruidas murallas de Barcelona ocupados en calles y plazas por el Excmo. Ayuntamiento de Barcelona. Valoración que se acompaña al plano de asentamiento de los solares que en los terrenos procedentes de las derruidas murallas de la ciudad de Barcelona, entregados a la Hacienda Civil en virtud de la Real Orden de 30 de enero de 1859, ha ocupado el Ayuntamiento en calles y plazas, cuyo importe por Real Orden 9 de diciembre de 1859 debe satisfacer para el Material de Ingenieros al objeto que en la misma Real Orden se expresa, resultando para dichos solares los precios que se detallan $y$ es el medio de la que se han vendido los contiguos, Barcelona 26 de febrero de 1881, ACA, Caja 404.

Comandancia GengRal Subinspeocion DE INGenibios. CataluÑa, In forme expediente relativo al Ordito del Estado contra el Ayuntamiento de Barcelona por terrenos de las murallas $y$ otros utilizados por vía pública, Barcelona 20 febrero 1891, ACA, Caja 404.

Convenio entre la GINDEF y el Excmo. Ayuntamiento de Gerona, por el que se regirán las entregas de diversas propriedades del Estado - Ramo de Defenisa-las contraprestaciones del Ayuntamiento, octubre de 1985. 
Convenio entre la GINDEF y el Excmo. Ayuntamiento de Barcelona, Barcelona, 1988.

Decreto 26 octubre 1868 autorizando al Ayuntamiento para la demolición de la Ciudadela y fuertes de la plaza de Barcelona, Archivo de la Corona de Aragón, Fondo Comand. Ing., Caja 352.

De La Llave y GaRcia, JoAquín, Nociones de Fortificación Permanente, Barcelona, Rev. Cient.-Mil., 1887-1888.

DUBY, G., Histoire de la France urbaine, Paris, Seuil, 1982.

Espaces et sociétés, 1979, núms 30/31, «Revalorisation des espaces. anciens».

EsTAPE, F., «El derribo de las murallas y la Barcelona del siglo XIX», en Miscellanea Barcinnonensia, Barcelona, 1967, núm. XVII, pp. 103-113.

FABo, M. 'y BARINAGA, R., «Los equipamientos colectivos en la ordenación del territorio», en Lurralde. Investigación y Espacio, 1983, pp. 389 -415 .

FerRnández ALBA, A. y Gavira, C., Crónicas del espacio perdido. La destrucción de la ciudad en España, 1960-1980, Monografias de la Dirección General Arquitectura y Edificacion, 1986, $135 \mathrm{pp}$.

FERNANDEZ BASTARRECHE, F., El Ejercito español en el siglo $\boldsymbol{X I X}$, Madrid, Siglo XXI, 1978, 189 pp.

Fontana, La Hacienda Española, Barcelona, Ariel, 1980.

FOURqUeT, F. y MURARD, L. M., Los equipamientos del poder. Ciudades, territorios y equipamientos colectivos, Barcelona, Gustavo Gili, 1978.

GOBIERNo MILITAR DE LA PROVINCIA DE BARCELONA, Dictando varias disposiciones referentes al derribo de las fortificaciones, 22 noviembre de 1868, Archivo de la Corona de Aragón, Fondo Comand. Ing., Caja 352.

GARCIA, A. y GUARDIA, M., Espai i Societat a la Barceloma pre-industrial, Barcelona, Ed. de la Magrana, IMH, 1987, 178 pp.

GRAU, R., «La metamorfosi de la ciutat enmurallada: Barcelona de Felip V a Ildefons Cerdá», en Cuaderns de Historia Económica de Catalunya, Barcelona, XX, 1979, octubre, pp. 49-58.

Informe acerca del derecho que asiste al Estado para ser indemnizado por el Ayuntamiento de Barcelona, por la ocupación de terrenos de las derruidas murallas de äicha capital $y$ del lienzo del cuartel de Atarazanas, Barcelona 26 febrero 1881, ACA, Caja 404.

LOPLE, P., El Centro Histórico: un lugar para el conflicto, Barcelona, Ed. de la Universidad, Col. Geo-Crítica, 1986, 191 pp.

LEFEVBRE, H., Espacio y politica. El derecho a la ciudad, II, Barcelona, Peninsula, 1976.

Ministerio DE DEFEnSA, Memoria de la Legislatura, 1986-1989, Madrid, Secretaria General Tecnica, Centro de Publicaciones, 1989.

MiNisterio DE IA GUUERA. DIRECciôn DE INGENIERos. Negociado 6, núm. 13, años 1884-1887. Cataluña, Sobre Derechos del Ramo de Guerra a dos terrenos en las murallas de Mar de Barcelona, ACA, Caja 404.

Ministerio DE LA GuterRa. 9 sección. Año 1891. Núm. 8. Cataluña, Crédito del Estado contra el Ayuntamiento de Barcelona por terrenos de las murallas, ACA, Caja 404. 
MURO MURales, J. IGNACIO, «Ciudad, fortificación y zonas polemicas en la España del siglo XIX», en CAPEL, H. (Coord.), Geografia y dominación social. Los espacios acotados, Barcelona, PPU, Col. Sociedad-Estado, 1990.

«Territorio $\mathrm{y}$ sociedad en el pensamiento militar del siglo XIX», en PESET, J. L. (Coord.), Ciencia, vida y espacio en Iberoamerica, Madrid, Tomo II, 1989.

El pensamiento militar sobre el territorio en la España contemponánea, Tesis Doctoral dirigida por cat. geografia humana Dr. HoRACIo CAPEL, Barcelona, 1990, 3 vols. (Madrid, Serv. Pub. Ministerio Defensa, 1991).

«Ingeniería militar y territorios polémicos en Cataluña. 1814-1854», comunicación presentada al Primer Congrés Catalá de Geografía, Barcelona, 11 al 15 marzo 1991, organizado por la Societat Catalana de Geografia, Institut d'Estudis Catalans.

NADAL, F., Burgueses, burócratas y territorio, Madrid, I. E. A. L., 1989. Navarro Segura, M. ISABEL, «La validez de una política de defensa de los centros históricos: los aspectos legales y de ordenación», en Ciudad y Territorio, 77-3, 1988, pp. 51-57.

RESOLUCIÓN DEL CONSEJO DE ESTADO, fecha 12 de diciembre 1890, sobre los terrenos de la antigua muralla de Barcelona, ocupados por calles del ensanche, publicada en la Gaceta de Madrid, nim. 91, fecha 1 abril 1891, en el pliego de resoluciones del Consejo de Estado, pp. 274-75, ACA, Caja 404.

ROdRigUbZ-VILLAaSANTE Y PRIETO, J. L., «El derecho urbanístico militar. Gestión y protección de los recursos inmobiliarios de la Defensa Nacional», en Revista Española de Derecho Militar, Escuela Militar de Estudios Jurídicos de la Defensa, 1987, núms. 44-50, pp. 11-57. SÁNCHEZ, J.-E., La geografía y el espacio social del poder, Barcelona, Los Libros de la Frontera, 1981, 248 pp.

SICA, P. (Dir.), Historia del Urbanismo, Madrid, I. E. A. L., 1981.

SOTERAS, ANA, «Defensa prepara la infraestrutura del siglo XXI», en Revista Española de Defensa, Año 4, núm. 35, enero 1991, pp. 6-11. URTEAGA, L., «El pensamiento higienista y la ciudad. La obra de P. F. Monlau (1808-1871)», en BONET CORREA, A., Urbanismo e historia urbana en el mundo hispánico. 2 Simposio, Madrid, Pub. Univ. Complutense, 1985, pp. 397-412.

URTEAGA, L. y NADAL, F., «Cartografía y Estado. La formación de una cartografía y una estadística nacionales», en Geo-Crítica, núm. 88, 1990,93 pp.

Valorar la História. Nova vida per a les velles ciutats, Generalitat de Catalunya, Departament de Politica Territorial i Obres Publiques, Barcelona, Imp. Pujagut, 1985.

Valorização Arquitectónica e Urbana de Lisboa, VALIS, Estudo promovido pela Comissão das Comunidades Europeias e realizado pelo Centro de Estudos e Desenvolvimento Regional e Urbano, Lda em Junho de 1990, Catálogo da Exposição. 


\section{RESUMO}

Transformações nos usos das propriedades militares em Espanha. Este artigo analisa um aspecto da política urbana do Estado espanhol em dois momentos historicos diferentes. $O$ objectivo $e ́$ analisar as mudanças no conceito de bem-público, entendido como um elemento sujeito a profundas transformações e a diferentes interpretações dentro do aparelho do Estado. No caso de património fundiário militar, objectivo central deste artigo, a questão é ainda mais complexa. Por esta razão realizámos uma análise comparativa de dois momentos históricos diferentes.

A primeira parte do artigo analisa a debilidade do Estado na questão da desafectação de grandes propriedades militares, associada primeiro com as instalações fortificadas e depois com a expansão urbana.

A segunda parte estuda o mesmo fenómeno mas como resultado do processo de modernização da administração pública, incluindo a militar. As necessidades de financiamento deste processo e o estabelecimento de critérios razoáveis de gestão da propriedade pública estão na base das decisões tomadas até agora. O resultado final destas mudanças, em Espanha, num plano mais geral, é ainda incerto. Todavia, à escala urbana não há dúvida de que estas mudanças implicaram uma revalorização de vastas áreas, reconvertidas, na sua maior parte, em novos bens de uso público.

\section{SUMMARY}

Changes in the uses of military land patrimony in Spain. - This article deals with one aspect of the State urban policy, in two diferent historical moments. The objective is to analyse the evolution in the concept of public good, seen as an element subject to deep changes and even different interpretations inside the state apparatus. The main object of this article is the military land patrimony. In this case the above mentioned question is even more complex. Therefore we have done a comparative analysis in two different historical situations.

The first part of the article analyses the weakness of central state in dealing firmly with the release of large military estate, associated, first, with the fortifications and, secondly, with the urban expansion.

The second part studies the same phenomenon but as a result of the modernization of public administration, including the military one. The financial needs of this process and the establishment of reasonable management criteria of the public propriety are in the base of all decisions taken so far. The final result of these changes, in Spain, in its more general level, is still uncertain. Nevertheless, at the urban scale, there is no doubt that these changes have implied a revalorization of large areas, reconverted, most of them, in new public facilities. 